\title{
Product differentiation and process flexibility as base for competitive strategy
}

\author{
H. A. Lepikson \\ Univ. Federal de Santa Catarina, Dept. of Mechanical Engineering \\ 88040-100 Florianópolis, Brazil \\ Phone: +55 (048) 231-9387, Fax: 234-1519, E-mail: \\ hal@grucon.ufsc.br
}

\begin{abstract}
One of the key problems faced by the companies nowadays is the management of their competitive positions is an increasingly more complex environment. This paper places a discussion in the strategic position of the companies and analyses the consequences originating from this position, mainly the imposed need to conciliate two conflicting elements of one manufacturing company: the profusion of new and differentiated products, in detriment of manufacturing economy, which demands large batches and slight changes in its planning in order to get the best performance. After a brief context analysis, an approach to this conciliation is evaluated, based on flexible product design and manufacturing, oriented by technological patterns and organizational culture to achieve this goal.
\end{abstract}

\section{Keywords}

Strategic planning, product design, flexible design and manufacturing, core competence

\section{INTRODUCTION}

The present market condition for industrial goods faces rapid and deep changes. The demand for more specialized products and its premature obsolescence impel companies to take a more flexible and dynamic attitude to face competition. In the companies' highest concerns the customers are no longer the same, nor are the workers or competitors. As markets expand worldwide, technological advancements exert a permanent pressure on products and their 
production process. The relations of the company to its environment have turned out to be very complex.

As a consequence, the traditional mass production concept is overshadowed by concerns with flexibility and competitiveness. Companies are giving more emphasis to quality and automation approaches to face the challenges set by these changing consumption patterns. But this is not enough, since these approaches are oriented to enhance existing stabilized systems. In order to cope with these new paradigms, companies need to deeply transform their product development structure and this must be also accompanied by transformations in the production system.

This paper deals with these transformation processes and suggests an integrated approach to face the challenge of assuring the survival of companies in a competitive environment on a long term basis. Rather than offering a "revolutionary approach", it shows how to put together known concepts in an effective way to generate real competitive advantage.

\section{PRODUCT DIFFERENTIATION AS STRATEGY}

There are two main generic strategies that are successful: total cost and differentiation leaderships (Porter, 1986). The strategy of total cost leadership is achieved by a number of functional policies set to this objective, like facilities to manufacture on an efficient scale, a strong effort towards cost reduction and control and minimum investments in areas such as R\&D, design, etc. This strategy, pursued by most companies, is characteristic of mass production industries, which utilize scale economy as their major weapon for competition.

The second strategic option sets out to differentiate the product the company offers, creating something considered unique in the industry, in proportions appreciated by the buyers. The differentiation may be done in product design, technology, peculiarities, ordered services or other dimensions. It allows a above average return, as it is paid off by its singularity, called premium price. Responding to these dimensions causes the products to be adapted to customer needs, with consequences in the production structure, as it favors the flexibility and the knowledge base on which it is sustained. A third option, focusing strategy, may be considered as a subset of one of the other two.

These strategies are not necessarily contradictory and could be used together (Day, 1989). Product quality may reduce costs as it increases the market share. As a consequence, gains are obtained in production scale. Cost is always an important factor: no matter how much the consumer may wish for a particular product, if cost is beyond his means, he will buy a cheaper one. However, as the company creates superior value for its clients, it can choose between obtaining a premium price for its advantages or have them transferred to a more competitive price, which will increase its market share (Clark 1993).

The two generic competition strategies take very different directions, but it may be concluded that they lead to only one result: what the customer really wishes for and tries to obtain is a differentiated product. Therefore, only product differentiation actually guarantees real competitive advantage in the long run. Cost strategy will always be a transitory advantage as it is easily followed by competitors. This paper seeks to analyse and suggest an approach for reorientation of strategies towards differentiation, with its implications on organizational flexibility. 


\subsection{Flexibility and competitiveness}

Flexibility is here understood as the ability of making fast, representative, changes in company's functions as result of the emerging needs. In order to develop their capacities for the differentiation strategy, the companies should direct their efforts to product development and manufacturing, with functional areas articulated towards client needs. From this "looking outside" it will be possible to develop products able to meet the real market demands and adjust the production structure to such a purpose. As a consequence, there comes an unavoidable need to turn to flexible production, according to reduced lot sizes, due to the variety of product options offered.

This conception is supported by the evidence that environmental uncertainty generates needs for flexibility and this induces developments in technology (Chen, 1992). As a consequence, this tends to increase the range of processes attended by flexible systems due to the breaking up of technological restrictions, accomplished by innovation. Companies that invest in product and process flexibility may expect to have a better response to environmental changes.

The question to be answered is how to introduce this differentiation strategy based on flexible production. In this introduction two concerns must be considered. First, it is essential to invest in advanced technology. But this alone is not enough and the frustrating efforts in CIM (Computer Integrated Manufacturing) in the last decade have proved that. In addition, it is necessary to have an organizational culture able to handle these technologies. The integration of both aspects is the key to the competitive leverage in the approach defended and discussed here.

\subsection{Technological aspects: flexible design and manufacturing}

Three technologies of advanced production systems are the core of the evolving process towards a differentiation strategy and they must be made available and integrated: CADComputer-Aided Design, GT- Group Technology, and FMC- Flexible Manufacturing Cells. The other areas will follow the orientation given by this three computer-aided technologies in a natural way.

$\mathrm{CAD}$ guides product development. But its potential will only be fully employed and will only be technically and economically justified if it is integrated in the productive process as a whole and in an integrated structure (Lepikson 1990a).

Among the options of automatic production, FMCs are the best adapted to the differentiation needs and recent technological advances are making FMC economically viable for many traditional processes (Chen, 1992). Its characteristics, if properly applied, allow fast adaptation to market conditions and possibility of gradual and modular implementation.

The GT is an already old concept that sets out to put together similar parts into families in order to optimize the many production stages. It is based on the recognition of similarities (in design or in process) and the memory of past problems with its solutions. However, GT has been traditionally used only as a supporting tool to process planning or to design. To make viable the approach here defended, GT has to be integrated first (and this is an internal question for every company). In this condition, it starts as the link joining the different views of integration. Figure 1 shows the role of GT and how the main different functions are interrelated. In this conception, GT disciplines and imposes restrictions on the many areas involved (Lepikson 1990a). 


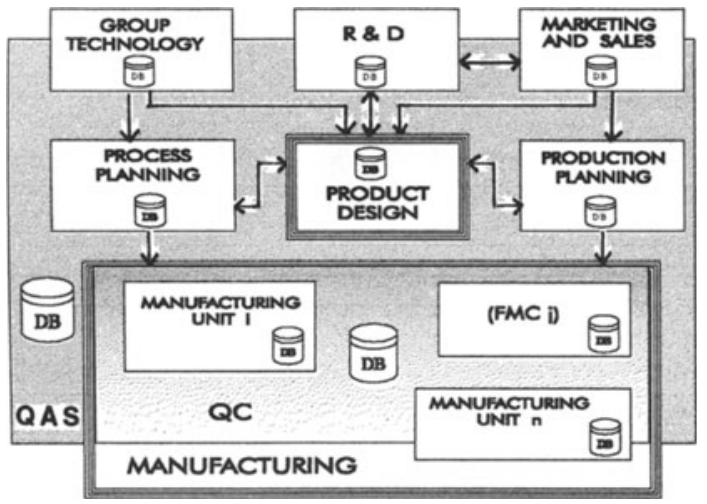

Figure 1 Basic interrelationship among areas directly related to product and its production.

In this sense the enclosing and feed-back role of the QAS (Quality Assurance System) is important to the whole production system and to the manufacturing function. QA shall be understood as a global function in the company, oriented towards the client. In this sense, every action in the company must be planned, controlled and audited, taking in account the QA objectives. QAS links the organizational culture to the technological frame in order to assure integration of the systems and to give direction to the technological demands.

The three technologies are the pillars and beams which build the system and QAS is a cement which plays a catalyst role. Nevertheless, in order to cope with their differentiated strategy demands, they need a new foundation to direct synergy towards technology. These are the company's core competencies (Prahalad, 1990). Core competencies constitute the set of resources and capacities absorbed by company's culture over a period of time and hold an important advantage for being unique, hard to imitate. Successful companies today must identify, develop and manage their core competencies to build their long term strategies. There are four outstanding aspects in this foundation on core competencies:

- it provides potential access to a large variety of markets with the same technological base;

- it favors technology flow and organizes work to obtain the optimum;

- it provides a significant contribution to the benefits noted by clients;

- it is difficult for competitors to imitate, due to the complex harmonization of individual technologies and competence generated in design and manufacturing.

A question to be solved is how to establish this unique competence, tuned in to the highly dynamic and turbulent environment in which the company is to survive and also how to take the fullest advantage of the situation, associating technological structure with organizational culture. This is done by the identification and development of core competencies based on technology management. In this case, technology is used to empower the company to face the rapid changes that its very policies have brought about (as it promotes innovation which competitors somehow try to follow). Technology adapts the company to changes and, at the same time, prepares for the necessary leap towards the future, strengthening its core competencies in a closed loop way. The company which has the best condition to promote the most frequent, and the best oriented technological advances in its production line (with the 
consequences in increased value and cost reduction that each advance means) will draw away, as the time goes by, from its competitors. The advantage obtained will be represented by higher profitability, higher market share, or both.

\subsection{The mean term: standardizing for the flexibility}

Although simple in conception, it is a nevertheless complex and wearing task to put this structure to work with positive synergy, specially considering the very different views of the same reality held by marketing, engineering and design. This approach allows greater holistic perception of the problems but also brings unavoidable conflicts.

Thinking first of operational basis, to have the system working effectively, it is important to associate it to standardization. Standards are essential to set processes in order, through an organized base on which the relationships are built. They are a strong point in the cost strategy and can be also useful for the differentiation strategy. In this way, GT offers, as shown, many advantages in disciplining the relations in the production system. It allows, from the very beginning, a unique language for communication and discipline in the relations between suppliers and customers.

Advantages are obtained through standardization of the product development philosophy itself. The development process of new products and its parts can be done by recovering the products and process histories, in a systematic way, taking advantage of similarity and modularity concepts (Pahl, 1988). This last item brings a number of implications (Logar, 1991). Among them, certainly the most important is the one regarding the power of features to support products by pre-configured design macros, with interfaces based on GT. This characteristic also results in elements to define FMCs that will feedback design. In this way, a great variety of product options can be obtained from limited design and manufacturing resources.

Concerning the manufacturing processes, unfortunately there is no way of preventing that production in small batches from raising the direct production cost. Strong integration of design with manufacture is necessary, including standards for processes, methods, and resources aiming at improvement in performance and reliability. The standardization of the parts to be manufactured become indispensable. The arraying of the entire system around families defined by the GT starts guiding not only design but also manufacturing and planning.

Many other implications occur. It is not difficult to observe what standardization means in term of economy in inventory, tools, molds, devices and so on. This perspective can be extended to the simplification of problems such as production routing and scheduling, material and supplier management, or to the potential role of standardization for building the manufacturing modules, assuring great evolutionary potential and low initial investments necessary to establish a system. The sum of these factors greatly compensates for the initial disadvantage of small batch production.

The contribution offered by the standardization to QAS is also important. The concept of design associated to GT offers rich potential in defining management and quality control standards, including the possibility of automatic generation of inspection programs (Krause, 1993). The feedback of design and production systems with data originated from QAS offers another important technological evolutive base to the existing patterns, as these data are the major primary sources for this feedback. This integrated conception is strongly dependent on a new distributed engineering database architecture, which is, in conception, at the same time robust (in selective access and retrieval of information meanings), real time access capable, able 
of showing different data versions and visions and transparent in relation to operational systems (Lepikson, 1990b).

\section{ORGANIZATIONAL CULTURE: THE FLEXIBLE ORGANIZATION}

Even nowadays, most organizational structures of companies follow a complex hierarchical models, whose articulation is very difficult. In this traditional structure, innovations are developed by the engineering department and commercialized by the sales people. This strategy, besides being a short term approach, overrates technical and economic aspects, relegating the customer to a secondary role. There are also distortions in the real understanding of the marketing concept. Too much emphasis is given to market surveys that contribute little to product innovation. After all, only what is already known can be surveyed. These surveys end up being worthwhile only to handle sales of products already well-known in the market, and this certainly is not the objective of a company who seeks differentiation.

The approach proposed is based on a structural and functional reformation. The tripod composed of marketing, industrial design, and engineering functions redefines each of the roles and its importance to the formulation of new strategic bases. These professionals start to work in a cooperative and integrated way seeking, therefore, an efficient strategic model aimed at efficiently attending market desires. Figure 2 shows how this is done, a concept that goes a little farther than those of concurrent or simultaneous engineering.

The marketing function has two primary purposes: (1) to detect market opportunities or inadequately satisfied demands by existing products and (2) to fulfill these spaces in an efficient way. This also involves the designers and engineers who will help to adjust the characteristics of the company's products to the ruling forces of the market.

The industrial design works between the technology (product development and manufacturing), and the market. It establishes a bridge between the customer and the company by converting the information obtained into desirable and useful products. Rather than dressing up the product, design helps to generate new concepts into new products in order to answer customers needs.

Engineering is connected to innovation, turning technology viable. Its role is well established in companies. Both design and engineering study the relationship between man and environment. While industrial design studies this relationship from the human point of view (physiological, psychological, and social conditions), engineering studies the physical, chemical, organic, and economical roles. Hence, they analyze the problems with different focusing. In other words, while engineering focuses on how to make product work, industrial design concentrates on making it readily usable (Harkins, 1994).

The engineering function must face the need for a deep structural change in order to prepare its professional for the market requests. Industrial design turns out to be a key element in the dialectic communication between marketing and engineering. Core competence acts as the embedded culture upon which the formal and informal relations are built and clear objectives are settled for the whole team. QAS interprets this culture and puts it on an operational basis, working with the performance factors (figure 2), which are made of quantitative and qualitative indices that measure and control the interfaces between functions These indices are built by the deployment of each element in the product and process modeling, using QFD (Quality Function Deployment) concepts (Krause, 1993). 




Figure 2 Relation of industrial design, engineering and marketing on product development.

The interpretation factor is involved in the product conception and is hard to deploy. Marketing must "feel" clients needs and be able to translate them to the industrial design which, in turn, must deploy desires into conception of products. Furthermore, this conception must be capable of being tested by potential clients. This means the capacity to bring together cultural context, human factors (even emotions) into one product. The conformity factor, on the other hand, brings rationality to the conception. It puts technical and economic questions into conceptions in order to make them viable as product It means design for manufacturability, pride in manufacturing. The utility factor translates conceptions into usable products as it introduces the human-product interface (pride of ownership, ease of use and maintenance, significant appearance, attractive aesthetic, good ergonomics, easy disposal at the end of life cycle).

These three performance factors induce the integration process and, in turn, build the company's core competence in a closed loop way which strengthens the technological base and the organization's culture.

\section{CONCLUSION}

The concept described represents the framework for the integration of the different functions within the company to accomplish its strategic objectives. This approach serves as the key concept for various projects dealing with the introduction and implementation of a differentiation strategy supported on a technological and organizational basis. This framework is not a collection of prescriptions made available to solve the operational or strategic problems of companies. It must be understood as an evolutive and educational matter, that can help companies interested in profound, progressive and consistent transformation on a long term basis.

The core competency plays an important role, as catalyst of the developed culture, that is beyond individual or even groups. It sets up the language, understanding, budgets, aims and so on. QAS is a global function which helps to support and develop the strategy and plays an important role in translating the core competency into operational basis. The computer-aided 
technologies are used to cope the required precision and velocity imposed by the environmental conditions. The organizational culture based on core competency causes the standardization process to be creative and evolutive, which is, by itself, an important conquest.

The impact of the consequent standardization process echoes throughout the whole company even to the clients and suppliers, developing a constructive relationship that really guarantees a competitive advantage that can hardly be surpassed by the competitors that use classic strategies for competition.

\section{REFERENCES}

Chen, I. Calantone R.J. and Chung, C.-H. (1992) The Marketing-Manufacturing Interface and Manufacturing Flexibility. Omega- International Journal of Management Science, 20/4, 432-3.

Clark, K.B. and Wheelwright, S.C. (1993) Managing New Product and Process Development. Macmillan - The Free Press, New York.

Day, G.S. (1989) Deciding How to Compete. Planning Review, sept./oct., 18-23.

Harkins, J.R. (1994) Is Design Doing its Job?, Machine Design, feb. 7, 53-8.

Juran, J.M and Gryna, F.M. Controle da Qualidade (Handbook). McGraw-Hill, São Paulo.

Krause, F.-L., Ulbrich A. and Woll, R. (1993) Methods for Quality-Driven Product Development, in Annals of CIRP, .42/1, 151-4.

Lepikson, H.A. (1990a) Padronização e Interação das Unidades de Fabricação, Manipulação e Inspeção de uma Célula Flexível de Fabricação. UFSC Dissertations, Florianópolis.

Lepikson, H.A. (1990b) Requisitos para Sistemas de Bases de Dados para Manufatura Automatizada, in Annals of 40 CONAI- Congresso Nacional de Automação Industrial, São Paulo.

Logar B. and Peklenik, J. (1991) Feature-Based Database Design and Automatic Forming of Part Families for GT, in Annals of the CIRP 40/1, 153-6.

Pahl G.and Beitz, W. (1988) Engineering Design: Systematic Approach. Springer Verlag, London.

Porter, M.E. (1986) Estratégia Competitiva. Campus, Rio de Janeiro.

Prahalad C.K. and Hamel, G. (1990) The Core Competence of the Corporations. Harvard Business Review, may-aug. 79-91.

\section{Biography}

Herman Augusto Lepikson, M.Sc.: Assistant Professor and Coordinator of the Industrial Automation and Metroloy Laboratory in the Department of Mechanical Engineering at the Federal University at Bahia State, Brazil. At the present, joining the GRUCON- Group on Industrial Automation and Numerical Controls in the Federal University at Santa Catarina State for a post-graduation program. 